\title{
Teorías de dependencia económica en el Caribe y Latinoamérica: un estudio comparativo ${ }^{1}$
}

\begin{abstract}
NORMAN GIRVAN, Profesor de la Universidad de West Indies en Jamaica, es autor de Foreign Capital and Economic Underdevelopment in Jamaica (1972); The Caribbean Bauxite Industry (1967) y Copper in Chile; a study in conflict between corporate and national economy. Es colaborador de Estudios Internacionales. Durante 1972 fue profesor visitante de CEPLAN en donde desarrolló este trabajo.
\end{abstract}

La búsqueda de una teoría económica del desarrollo aceptable, ha sido intensa durante el período de post-guerra, alcanzándose grados variables de éxito. Este ensayo ${ }^{2}$ investiga algunas contribuciones provenientes de América Latina y del Caribe de habla inglesa, basadas en el concepto de dependencia externa y de la institucionalización del subdesarrollo. Espero demostrar que hay una similitud subyacente en la metodología de las dos escuelas de pensamiento, que nacieron virtualmente en forma independiente la una de la otra. Esta similitud deriva de una necesidad común de encontrar un marco de referencia teórico apropiado para la interpretación y análisis del proceso económico de ambas regiones. Se argumenta que el desarrollo de la "teoría económica de la dependencia" en el fondo es una respuesta a la dinámica de los cambios sociales y económicos en ambas regiones: sin embargo, verdaderamente es una parte del proceso de cambios mismos. Las semejanzas, las diferencias y la creciente convergencia de la teoría de la dependencia en ambas regiones, refleja similitudes y discrepancias en los términos sobre los cuales las dos

${ }^{1}$ Este trabajo se publica conjuntamente con El Trimestre Económico, México.

${ }^{2}$ Este ensayo es una versión revisada de "El desarrollo de la dependencia en América Latina y el Caribe" presentado en la Conferencia sobre Dependencia Externa y Problemas del Desarrollo en América Latina y en èl Caribe, patrocinado por el Comité de Estudios Latinoamericanos de la Universidad de Toronto en Abril 1972. Deseo agradecer a Myron Frankman, Havelock Brewster y Osvaldo Sunkel por sus comentarios sobre la versión preliminar. Agradezco también al Centro de Estudios de Planificación de la Universidad Católica de Chile (CEPLAN) por las facilidades prestadas para la revisión del trabajo. 
regiones fueron incorporadas a la economía internacional, y la creciente convergencia de la naturaleza de su dependencia y su subdesarrollo en el período contemporáneo. Ambas escuelas de pensamiento han proporcionado poderosos elementos de comprensión del proceso de desarrollo y subdesarrollo en el Nuevo Mundo.

Algunas implicaciones interesantes parecen surgir de este ejercicio. Primero, los métodos de análisis desarrollados podrían resultar de utilidad en el estudio del subdesarrollo en otras regiones del Tercer Mundo. En segundo término, la búsqueda de una teoría autóctona conduce, paso a paso, al reconocimiento de la necesidad de redefinir la naturaleza del sistema económico internacional y de lás economías metropolitanas mismas en forma tal que explique mejor la evolución de las economías dependientes. Finalmente, se sugieren algunas implicaciones para la definición de estrategias de desarrollo para los países subdesarrollados dependientes.

El tema de este trabajo se puede dividir en dos partes generales. Ia primera examina la emergencia de un modelo de desarrollo de post-guerra, que representa el rechazo del modelo de exportación de productos primarios y los argumentos a favor de la industrialización. Además se discuten las reacciones más recientes a las fallas del modelo, especialmente en la forma del desarrollo de escuelas de integración económica en ambas regiones.

La segunda parte se refiere a la emergencia de las escuelas de "dependencia"; y el uso del método histórico-estructural-institucional para diagnosticar las causas fundamentales del subdesarrollo. Por último, una breve sección de conclusiones señala algunas implicaciones finales de los resultados.

I. EL MODELO DE D. SARROLLO DE POST-GUERRA

Y SUS FRUSTRACIONES

\section{La Necesidad de Industrialización}

En 1949 fue publicado el muy celebrado libro de Prebisch " $E l$ Desarrollo Económico de América Latina y sus Problemas Principales". En él argumenta contra la continua dependencia de América Latina de las exportaciones de bienes primarios para sostener la dinámica del crecimiento, y la necesidad de la industrialización como alternativa. El curso de los acontecimientos durante el siglo 20 había hecho que los modelos de especialización internacional del siglo pasado quedaran obsoletos y, que la industrialización fuese estructuralmente inevitable. Así: 
"En América Latina, la realidad está debilitando el esquema elaborado sobre la división internacional del trabajo, que tuvo gran importancia durante el siglo 19, y que como concepto teórico tuvo influencia hasta hace poco. Bajo este esquema, la tarea especifica que recayó sobre América Latina, como parte de la periferia del sistema económico mundial fue la de producir alimentos y materias primas para los grandes centros industriales".

"No habrá lugar dentro de él para la industrialización de estos países nuevos. Sin embargo, las circunstancias la fuerzan. Dos guerras mundiales en una misma generación y una gran crisis económica entre ellas dos, ha mostrado a los países latinoamericanos su oportunidad que apunta claramente hacia la actividad industrial". 3

La hemamienta teórica principal del análisis de Prebisch es la incidencia del progreso técnico y el correspondiente crecimiento de productividad. La teoría subyacente al esquema tradicional de la división internacional del trabajo supone que los productores de bienes primarios, por un lado, y de bienes industriales, por otro, compartirían equitativamente los aumentos de productividad resultantes de la especialización internacional y progreso técnico. En realidad, sin embargo, los países industriales centrales se apropiaban de los beneficios, debido a aumentos de productividad, que ocurrían, ya sea en el centro, o en la periferia. La evidencia tuvo que ser encontrada en la tendencia secularmente adversa de los términos de intercambio experimentada por los países primario-productores; la razón de esto fue, en cambio, explicada en términos de movimientos diferenciados de precios paxa los bienes industriales versus los bienes primarios, producidos por los altibajos del ciclo económico. ${ }^{4}$ La industrialización fue la única alternativa para la Periferia, el "principal medio a disposición de estos países para obtener una parte de los beneficios del progreso técnico y del aumento progresivo del standard de vida de las masas"."

Puesto que la industria manufacturera tuvo que ser adecuada a la producción de bienes previamente importados, el modelo de desarroIIo de post-guerra se pasó a llamar "industrialización sustitutiva". Lo que pudiese parecer una coincidencia, es el hecho de que en el mismo tiempo en que Prebisch abogaba por la industrialización latinoamericana, W. Arthur Lewis hacía lo mismo para las Indias Occidentales. Su libro "Industrialization of the British West Indies", publicado en 1950, al igual que el de Prebisch se convirtió en un clásico. La preocupación principal de Lewis era la generación de pleno empleo en esta área. Su análisis hace uso principalmente de

${ }^{3}$ Ref. (1), p. 1 (énfasis agregado).

Ver Ref. (1) para una descripción del mecanismo.

I Ibid. 
dos herramientas; el balance tierra-población, y una teoría revisada de las ventajas comparativas. La necesidad de industrialización nació principalmente por una dotación desfavorable de tierra versus poplación. Así:

"La necesidad de una rápida industrialización en las Indias Occidentales descansa principalmente en la sobre-población. Las islas ya muestran que la población es mayor a lo que la agricultura puede absorber. Ia población crece a tasas de 1,5 a 2,0 por ciento anual. Es urgente, por tanto, crear nuevas oportunidades de trabajo fuera del sector agrícola". 6

Sin embargo, esta "sobre-población" da origen a ventajas comparativas, para las Indias Occidentales en manufacturas intensivas en mano de obra, en relación a los países industriales desarrollados donde la mano de obra es un recurso escaso y caro. Así, las Indias Occidentales, deberían buscar el desarrollo en un nuevo comercio de exportación especializado en manufacturas intensivas en mano de obra hacia mercados metropolitanos. Este sería un paso hacia el cumplimiento de las metas de pleno empleo. Como los empresarios nacionales no tienen ni el capital ni las conexiones de mercado necesarias para esta tarea, el peso del esfuerzo del desarrollo industrial caería sobre inversionistas extranjeros. Pero, esto implicaba un importante papel de parte del gobierno, para inducir la entrada de capitalistas y proveer la infraestructura necesaria y otras facilidades. Este modelo llegó a conocerse como "industrialización por invitación".

La emergencia simultánea de teorías de industrialización, en América Latina y en el Caribe fue, en la perspectiva histórica, más que una nueva coincidencia. Los sucesos acaecidos durante los años 30 en ambas regiones mostraron que la economía política tradicional no era viable en términos políticos ni económicos. Más aún, éstos tenían en ambas regiones una causa común: el colapso total y catastrófico de la economía capitalista internacional precipitado por la crisis en Ios Estados Unidos en 1929. EI resultado de esto fue una severa contracción de la demanda, precios y producción de bienes primarios de los cuales América Latina y las Indias Occidentales dependian. En América Latina esto ocasionó el rápido desplazamiento de gobiernos comprometidos con el laissez-faire y la prevaleciente división internacional del trabajo, por regímenes comprometidos con la intervención gubernamental en la economía para el mantenimiento de niveles de ingreso nacional y empleo, y finalmente, con la promoción del crecimiento económico y el desarrollo. Estas políticas indujeron en cierto grado a la llamada "industrialización

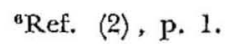


involuntaria"7: la preocupación de Prebisch era legitimar el proceso con una nueva teoría, y así ayudar que sea consciente, oficial y deliberado. ${ }^{8}$

También en el Caribe las fuerzas del cambio se dirigieron primeramente en contra de los políticos antes de afectar lo económico. La diferencia fue que la región aún estaba bajo el dominio colonial, por lo que la demanda popular para un mejoramiento económico se reflejó en las revueltas y huelgas de 1937-38 que fue efectivamente canalizada por la élite de colonos educados en demanda de autonomía política. La transición hacia la autonomía e independencia comenzó con la incorporación de líderes políticos locales en la administración colonial después de la guerra, y además por la aceptación de cierta responsabilidad de aquellas administraciones por el desarrollo social y económico.

En ambas regiones, por tanto, existía la clara necesidad dé una nueva teoría económica para servir la nueva política. El análisis contra la especialización en productos primarios debía reinterpretar la teoría de la especialización internacional (Lewis) o cuestionar sus supuestos (Prebisch). Esto significaba ir contra el formidable aparato de la economía convencional y sus vastos intereses; vastos intereses intelectuales no menos que económicos y políticos. Ambos autores proveen una justificación para la activa intervención gubernamental en la economía como apoyo al esfuerzo de industrialización acometido por el sector privado. Quizás más importante -a la luz de hechos siguientes- ambos suponen que la industrialización establecería las bases para la emergencia de economías genuinamente nacionales en la región: o sea, que sería estratégico internalizar la dinámicá del proceso de crecimiento. Para Prebisch el carácter distintivo principal del Centro respecto de la Periferia es una industria manufacturera desarrollada; una vez que la periferia se industrializa, se puede (como seguramente lo hará) internalizar el proceso de crecimiento de la productividad que es el ingrediente básico del crecimiento económico. Por otra parte, Lewis previó el desarrollo de dos fenómenos que contribuirían a la internalización suave del proceso de crecimiento en las Indias Occidentales. Primero, el crecimiento del ingreso nacional per cápita resultante de la industrialización

TRealmente, en algunos paises como Argentina y Brasil, el proceso de industrialización comenzó a fines del siglo pasado, con la producción de artículos sim. ples para el consumo.

${ }^{3}$ Dos Santos dice que "...la ideología desarrollista y nacionalista llegó a ser dominante como resultado de los intereses de clase que ésta refleja en su forma más pura. Esto es, la burguesía industrial formada en los años 30, en un periodo de debilitamiento del capital extranjero en América Latina ... se ha convertido en la clase dominante en nuestros países." Dependencia y Cambio Social, Santiago, CESO, 1970, pp. 27-28. 
aumentaría la capacidad nàcional para ahorrar y (por tanto) para invertir; secundariamente, el efecto demostración de la presencia de inversionistas extranjeros en la economía enseñaría a los empresarios nacionales "los trucos del comercio".

\section{Dependencia, Tamaño Pequeño y la Necesidad de Integración Eco- nómica del Caribe}

Hemos visto que a pesar de las distintas herramientas de análisis empleadas por Lewis y Prebisch, ambos llegan a las mismas conclusiones en términos de política. Una de las principales diferencias de conceptuación fue la concepción de Prebisch de la economía internacional como un sistema Centro-Periférico. En esta conceptualización va implícito el sentido de dependencia de la Periferia. ${ }^{9}$ Es claro, sin embargo, que una de las preocupaciones principales de Prebisch era que la tasa y modelo de desarrollo de América Latina no podía continuar siendo un reflejo del desarrollo de los Centros industriales. El tema de dependencia económica no apareció en el Caribe, sin embargo, hasta principios de los años 60 . Fue en este período, que comenzó a considerarse dicho elemento como el rasgo dominante de la estructura y funcionamiento de las economías del Caribe, por parte de un grupo de economistas asociados con el New World Group y de la Universidad de West Indies: Así algunos asociados a este grupo'10, Thomas ${ }^{11}$ y Mc Intyre ${ }^{12}$ comenzaron por describir la economía como "dependiente" del resto del mundo a través de los mercados de capital, abastecimientos, habilidades y especialización, sèrvicios bancarios y financieros y por la mantención $y$ crecimiento del empleo, producto y demanda internos.

Es posible encontrar una explicación al hecho de que el estudio de las relaciones de dependencia apareciera en el Caribe una década más tarde que en Américá Latina. Esto se puede haber debido simplemente a la influencia tardía del pensamiento de CEPAT fuera de América Latina. Pero hay otras razones asociadas al contexto político y a la situación económica del Caribe. Para comenzar, las exportaciones agrícolas de las Indias Occidentales gozaban de un mercado altamente protegido en el Reino Unido durante los años 40 y principios del 50, como resultado del retorno parcial a la autosuficiencia por parte del Imperio Británico después de la crisis del

"El hecho de que Prebisch no haya empleado realmente la palabra "dependencia" es irrelevante para este propósito.

${ }^{10}$ Ref. (3) .

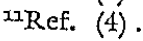

${ }^{12}$ Ref. (5). 
año 30. Por tanto durante este período el peligro de la inestabilidad de las exportaciones en el Caribe fue menor que en América Latina. Sin embargo, el desmantelamiento progresivo de preferencias otorgadas por el Reino Unido y Canadá, y el interés de los británicos en el ingreso al Mercado Común Europeo, llevó a algunos observadores a cuestionar la viabilidad y valor del sistema preferencial en sí mismo ${ }^{13}$. Secundariamente, se hizo evidente para un número creciente de economistas en la región que la "Industrialización por Invitación" fallaba en la solución al problema del desempleo, ni tampoco mostraba signos de internalizar la dinámica del crecimiento. Un tercer factor tenía que ver con el desarrollo político. La obtención de independencia política por un gran número de países en la región a principios de los años 60 , hizo surgir una aguda contradicción entre la forma constitucional y la realidad económica. Así en $1964 \mathrm{Mc}$ Intyre observa que:

"Una de las características más relevantes del desarrollo de las Indias Occidentales reside en que el progreso hacia la independencia política no ha sido acompañado por un avance paralelo en el campo económico... Los territorios de. Ias Indias Occidentales aún se miran como los mayores ejemplos de economías dependientes". ${ }^{14}$

Esta conciencia sobre el éxito limitado de la "Industrialización por Invitación" y del alto grado de dependencia externa en las economías de la región, trajo consigo como preocupación, la necesidad de la Integración Económica Regional. En el mismo artículo Mc Intyre hace una contribución importante para el pensamiento de este problema. Empieza por distinguir entre:

"dependencia estructural: la dependencia producida por el tamaño y estructura de la economía que no puede ser solucionada, y

"dependencia funcional: la dependencia producida como resultado de políticas particulares elegidas y que, por tanto, pueden evadirse si se dan políticas alternativas... Estos no son categorías mutuamente excluyentes, pero para este propósito conviene tratarlas como tales". 15

$\mathrm{Su}$ argumento fue que la preocupación de los políticos de las Indias Occidentales en la mantención del sistema preferencial manifestaba una dependencia funcional. La tendencia de las políticas británicas y canadienses era hacia el desmantelamiento de preferencias: de todas formas, el efecto de las preferencias era el de proteger la producción a altos costos de las Indias Occidentales de la competencia mundial, y de actuar como un incentivo negativo en la expan-

${ }^{13}$ Mc Intyre, Ref. (5).

${ }^{21}$ Mc Intyre, Ref. (5), p. 165.

atrbid., p. 166. 
sión de la industria manufacturera. Era mucho mejor concentrar los esfuerzos en el diseño de políticas de comercio exterior encaminadas al logro de una integración económica de la región. El argumento de Mc Intyre para la integración no se basó en la teoría metropolitana neo-clásica de las uniones aduaneras, que era irrelevante para la economía del Caribe, y por tanto de poco valor comoguía de una política de integración, sino en aproximaciones alternativas teóricas y prácticas.

Dicho artículo está permeado de la conciencia sobre la necesidad. de desarrollar un aparato teórico autóctono, una conciencia que fue el carácter prominente de la teoría económica en el Garibe durante los años 60. Su argumento a favor de la integración económica regional como un medio de alivio de las frustraciones que surgieron por la falla de la Industrialización por Invitación, tiene una importante contrapartida en el pensamiento económico de América Latina, como veremos, y de hecho la experiencia latinoamericana jugó un papel influyente en el desarrollo del pensamiento de integración de las Indias Occidentales. Pero en la situación posterior hubo una dimensión-adicional: una conciencia aguda sobre las limitaciones impuestas por el pequeño tamaño de las economías. Mc Intyre definió la dependencia estructural como aquella que surge debido al "tamaño y estructura de la economía y que no puede ser eliminada". La visión implícita de que la dependencia estructural en el Caribe está condicionada por alguna variable "natural" tal como el tamaño, y por tanto inescapable en algún grado, ha ejercido una poderosa influencia. sobre el pensamiento económico en la región.

Esta tendencia en el pensamiento económico del Caribe alcanzó su máxima expresión teórica en el trabajo de Demas (1965) sobre "The Economics of Development in Small Countries with special reference to the Caribbean". Este trabajo está esencialmente inspirado por la necesidad de desarrollar un esquema teórico para explicar la falla de las economías de las Indias Occidentales para lograr un crecimiento "autosostenido", eliminar el desempleo a gran escala, y reducir significativamente la estructura de dependencia; después de casi 20 años de políticas económicas en ese sentido por parte del Gobierno. El esquema desarrollado hace uso del concepto de transformación económica ${ }^{16}$, y de las restricciones a aquella transformación impuesta por el pequeño tamaño económico ${ }^{17}$. La pequeñez de los mercados nacionales significa que el país debe especializarse en la producción de un pequeño número de bienes para exportar al mercado mundial, para así asegurarse beneficios de econornía a

${ }^{16}$ Siete índices de transformación son usados. Ver Ref. $(6)$.

${ }^{27}$ Definido en términos de población y de superficie. 
escala. Ia concentrada base de recursos implica que una alta proporción de bienes intermedios y de capital debe ser importado para poder así eliminar las brechas en la estructura de producción nacional... En un mayor grado que las economías grandes, por tanto, las pequeñas economías deben depender del comercio internacional para asegurar el desarrollo económico. Como resultado, su dependencia de los gustos y decisiones de consumidores extranjeros y productores, y de la tecnología externa y cambios técnicos, serán inevitablemente mayores. La capacidad, por tanto, de países pequeños para transformar plenamente su estructura de producción, y sostener su propio desarrollo endógenamente, está significativamente limitado por el solo hecho del tamaño. Estas limitaciones imparten una urgencia especial a políticas de integración económica regional: tales políticas, expandiendo el tamaño efectivo de las economías, aumentarán las posibilidades de una transformación estructural.

En gran parte como resultado del trabajo de Mc Intyre y Demas, 1a Integración Económica Regional reemplazó a la Industrialización por Invitación como el modelo de desarrollo en boga en círculos académicos en el Caribe a mediados de los años 60. Un equipo de economistas de la universidad regional produjo una serie de estudios, documentando las posibilidades empíricas para el desarrollo de las actividades básicas de la agricultura y de la actividad industrial; y la racionalización del sector de exportaciones, sustentado en un programa de integración funcional y sectorial en la región 18. Este proceso alcanzó su máxima expresión teórica en el trabajo de Brewster y Thomas ${ }^{19}$ que sostuvo que para economías dependientes y subdesarrolladas la teoría económica de la integración era realmente una parte de la teoría de desarrollo y de transformación estructural. El impacto de tal pensamiento, se reflejó en alguna medida en la creación de la Asociación de Libre Comercio del Caribe (CARIFTA) en $1968: 20$

${ }^{18}$ Studies in Regional Economic Integration, Vols. I y 2, Mona, Instituto de Investigaciones Económicas y Sociales, Universidad de las Indias Occidentales, 1967.

${ }^{10}$ Ref. (7) .

${ }^{20} \mathrm{El}$ trabajo académico que legitimaba las políticas de integración regional coincidió con la necesidad del Gobierno de las Indias Occidentales de encontrar políticas económicas nuevas y con las presiones de. Ios grupos manufactureros de las Indias Occidentales para liberar el comercio entre los territorios. Sin embargo, la GARIFTA contempló la aplicación de muy pocas de 'las políticas funcionales y sectoriales que habian sido promovidas en los estudios previos de integración; los gobiernos la concibieron más como un complemento a la Industrialización por Invitación, que como un sustituto. 
La Estrangulación del Sector de Exportaciones y la Necesidad de la Integración Económica Latinoamericana

Es interesante examinar las diferencias y semejanzas en el desarrollo latinoamericano en los años 50 y comienzos del 60. A fines de los años 50, se comenzó a disipar el optimismo inicial acerca del éxito de la industrialización sustitutiva. Para comenzar, la mayoría de los países de la región no habían experimentado ningún crecimiento significativo. El proceso de industrialización se había limitado a un pequeño número de países, especialmente Brasil, Argentina, Chile y México, con mercados internos suficientemente grandes en términos de población y/o poder de compra. Aun en estos países (excepto México debido a circunstancias especiales) el ritmo del crecimiento industrial había aflojado considerablemente. Una de las razones principales para explicar esta situación, fue la limitante impuesta por el tamaño del mercado. Los paises que experimentaron un crecimiento industrial significativo habían superado la etapa de sustitución de importaciones "fáciles", y tenían dificultades para proceder a la manufactura de bienes intermedios o finales; cuya producción es más intensiva en capital, y su volumen óptimo de producción es mayor que aquel que los mercados nacionaleś podían absorber. Los mercados en los países pequeños y/o de bajos ingresos, eran demasiado estrechos para soportar plenamente la fase de sustituir importaciones "fáciles" 21 . No es difícil observar que un análisis que considera el tamaño del mercado como un obstáculo importante para el crecimiento industrial, implica la necesidad de una política conducente a la expansión de dicho tamaño. A principios de 1960 la integración económica en América Latina llegó a ser vista como un instrumento de gran importancia para tal politica: en las palabras de GEPAL “... la extensión de mercados nacionales se presentaba como una medida esencial para la satisfacción de los requerimientos básicos de avance hacia etapas superiores de industrialización" ${ }^{\prime 22}$. En esta medida, las primeras reacciones ante el éxito limitado de políticas de industrialización de post-guerra fueron similares en el Caribe $y$ en América Latina.

Pero en la situación latinoamericana hubo un factor adicional que imprimía urgencia a la necesidad de una integración económica;

"Vex María de Conceição "Tavares, "Growth and Decline of the Process of Import Substitution in Brazil", Economic Bulletin for L. A., Vol. IX, No -1, marzo 1964; Andrés Bianchi, "Notas sobre la teoría del desarrollo económico latinoamericano" en A. Bianchi (ed.) América Latina: Ensayos de Interpretación Económica, Santiago, Edit. Universitaria, 1969. Ver Ref. (I2).

${ }^{22}$ Ref. $(7)$, pp. 36-37. 
tal como lo percibía la escuela de Cepal23. Esto fue el llamado estrangulamiento del sector externo, que reflejaba los desequilibrios de Balanza de Pagos que venían siendo experimentados; especialmente por los países más industrializados. El proceso de sustitución de importaciones no alcanzó a afectar la estructura tradicional de exportaciones; que se mantuvo compuesta casi exclusivamente por un pequeño número de productos primarios. Los términos de intercambio, habian continuado deteriorándose y el crecimiento de exportaciones fue lento. Por otro lado el proceso de industrialización creó nuevas y crecientes demandas de importaciones: primero, de bienes de capital e intermedios para el mismo sector industrial; segundo, de bienes de consumo requeridos para satisfacer la nueva y diversificada demanda de los grupos cuyo ingreso había aumentado. También existía la necesidad de financiar la pesada carga que significaba la inversión privada extranjera y la deuda externa. Así la continuación del proceso de industrialización y crecimiento económico se hizo criticamente dependiente del ingreso de divisas. El aumento de la deuda externa en el corto plazo podría ser beneficioso pero sólo agravaría el problema en el mediano y largo plazo. Se necesitaba crear un sector de exportaciones flexible y dinámico. Dadas las actitudes proteccionistas de los países inclustriales desarrollados, significaba que la integración regional "aparece como la única solución efectiva para la creación de nuevos impulsos dinámicos y de otra estructura nacional de crecimiento más flexible y productiva que aquella lograda por el proceso de industrialización sustitutiva"24. Al mismo tiempo, la CEPAI seguia ejerciendo sus presiones, sobre todo en foros mundiales, como UNCTAD, para el relajamiento de las restricciones de comercio para las exportaciones de los países latinoamericanos de parte de los países desarrollados, y de un mayor flujo financiero de ellos en términos más favorables ${ }^{25}$. Esto facilitaría el crecimiento de nuevas exportaciones latinoamericanas hacia los países desarrollados e incrementaría los ingresos de divisas en la cuenta capital. La Cepal mantuvo una doble estrategia de presión y persuasión en los años 60: la primera sobre gobiernos latinoamericanos en favor de la integración regional; la segunda sobre gobiernos de países desarrollados para un comercio y políticas financieras más liberales. Esta estrategia siguió lógicamente de un análisis que aceptaba como supuesto básico el funcionamiento del modelo de industrialización de post-guerra, e identificaba el estrangulamiento del

${ }^{2 \pi}$ Ref. (8) especialmente cap. 5.

${ }^{24}$ Ref. (8), pp. 169-170.

${ }^{25}$ Ver: por ejemplo, Discurso de C. Quintana, Secretario Ejecutivo de Cepal, en UNCTAD II, Nueva. Dehli,. 1968. Ref. (8), Cap. VIIr. 
sector externo como el mayor obstáculo para su pleno desarrollo: ${ }^{26}$

Resumiendo, se podría decir que la emergencia de las escuelas de integración económica en ambas regiones, fue estimulada por la necesidad de encontrar la solución a los problemas planteados por el éxito limitado del modelo de industrialización de post-guerra. En el Caribe, además, existía la conciencia de las limitaciones planteadas por el tamaño; en cambio en América Latina existía la conciencia de los obstáculos presentados por el estrangulamiento del sector externo. Esta discrepancia se puede explicar simplemente en términos de circunstancias distintas. Es cierto, que en América Latina, la faltà relativa de industrialización en los países pequeños, como aquellos de Centroamérica, se explicaba en parte debido a la pequeñez. Sin embargo, el tamaño pequeño, por sí, no podía asumir un lugar dominante en la explicación de las dificultades experimentadas en la continuación del proceso de industrialización en países como Brasil y Argentina e incluso Chile, Perú y Colombia ${ }^{27}$. Por otro lado, en las Indias Occidentales, no existía el problema de estrangulación del sector externo en el mismo sentido latinomericano. El sistema monetario abierto significaba que las condiciones del sector externo tendían a afectar los niveles de demanda internos, producto y directamente al empleo: en vez de significar una reducción de divisas como tales. En cualquier caso, las Indias Occidentales, durante los años 50 y 60 generalmente experimentaron buenas condiciones del sector externo. Algunos "antiguos" sectores de exportación recibieron ayuda del Reino Unido, algunos "nuevos" tales como la bauxita, turismo, petróleo, estaban expandiéndose rápidamente y muchas de las islas más pequeñas recibieron una ayuda financiera sustancial del sector público del Reino Unido.

Sin embargo, a pesar de que las diferencias se pueden explicar en términos simples, tienen implicaciones más profundas. Si países latinoamericanos relativamente grandes están teniendo dificultades al diversificar sus exportaciones y logrando un crecimiento autosostenido, podría ser que el tamaño no fuese crucialmente un obstáculo

${ }^{2 \theta}$ Cepal también señala otros factores que impiden el proceso de crecimiento, tal como:

i) La falta de movilidad social y la extrema desigualdad de distribución del ingreso y propiedad.

ii) El lentó avance hacia la creación de un sistema de planificación y adopción de políticas ejecutivas y efectivas.

iii) El atraso y estancamiento de la economia rural.

iv) La debilidad financiera del sector público, resultante del sistema retrógrado de imposiciones y el estancamiento de las exportaciones.

v) Desequilibrio financiero y monetario manifestado en una fuerte inflación.

Ref. (8), pp. 170-171.

"Se debe observar que Demas define "pats pequeño" como aquel con menos de 5 millones de personas y 20.000 millas cuadradas de territorio. 
Norman Girvan / Teorfas de dependencia económica en el Caribe y Latinoamérica

al crecimiento autosostenido, tal como es presentado por algunos teóricos del Caribe. Si los países del Caribe han tenido dificultades en sostener su propio crecimiento industrial no obstante la buena situación de su sector de exportaciones, podría ser que el estrangulamiento de éste sea menos importante como obstáculo para la transformación del sector industrial como se piensa para el caso americano. Se podría, por supuesto, decir que lo que se necesita es una combinación de tamaño grande con condiciones favorables de exportación, o sea del tipo de un Brasil Jamaicano, o para ser más realistas, México. Sin embargo, estas preguntas sirven para iniciar un análisis de algunos nuevos principios en el pensamientó económico, que empezaron a surgir en ambas regiones. Este pensamiento tendía a visualizar los obstáculos del tamaño pequeño y la estrangulación del sector exportaciones como las manifestaciones superficiales de un proceso económico característico de la economía contemporánea, - pasada. En la siguiente examinaremos la evolución y algunas de las características del nuevo enfoque en América Latina y en el Caribe. ${ }^{28}$

\section{DEPENDENGIA ECONÓMICA Y EL ENFOQUE HISTÓRICO- ESTRUCTURAL-INSTITUCIONAL}

\section{El Concepto de Dependencia Económica}

En la formulación de Cepal sobre el estrangulamiento del sector de exportaciones como la causa principal de la crisis económica latinoamericana, estaba implícito el reconocimiento del rol estratégico jugado, por las relaciones económicas internacionales como un factor permisivo en el proceso de desarrollos. El tema de la dependencia económica como tal fue poco explícito. En una conferencia en 1966, Sunkel observa que... "si uno examina los escritos en América Latina, la dependencia externa como tema está ausente... En contraste con la falta de investigación seria sobre este importante tópico, la discusión pública y la controversia partidista abundan..."29. Comenzando la tarea de hacer explícito el tema, Sunkel diagnostica principalmente cuatro "mecanismos de dependencia":

i) EI estancamiento de la agricultura, que implica un lento creci-

\footnotetext{
${ }^{28} \mathrm{Se}$ reconoce que este "nuevo enfoque" en ambas regiones nació del pensamiento e investigación asociada con el modelo de industrialización de post-guerra, y tiene muchas caracteristicas con este último. Se señala la diferencia principalmente para facilitar la presentación y el análisis.
}

${ }^{29}$ Ref. (9) . 
miento de las exportaciones agrícolas y un aumento rápido de las importaciones de alimentos.

ii) La escasa diversificación de las exportaciones.

iii) El alto contenido de divisas de la industrialización que requería del pago tanto de servicios, como de bienes debido al grado de propiedad extranjera en la industria, y

iv) El déficit fiscal creciente, debido al estancamiento de la exportación agrícola tradicional ante la creciente importancia del sector público; lo que significaba un aumento constante de la deuda pública externa. "Is este aspecto - la necesidad opresora e implacable de obtener financiamiento externo- el que finalmente conforma la situación de dependencia; este es el punto crucial del mecanismo de la dependencia". 30

Tal dependencia es contrastada con la necesidad de una política para un desarrollo auténticamente nacional; o sea, una que evite las opciones falsas entre revolución socialista "y pais de subsidiarias de corporaciones multinacionales", que los principales campos ideológicos mundiales desean imponer en América Latina; y que tenga éxito en asegurar una participación creciente en la vida nacional de los grupos socio-políticos y clase sociales, "más y más representativos de la nación, sus tradiciones, cultura, valores, instituciones e historia"31. Tal desarrollo no resulta como la mágica consecuencia de algún acto heroico, sino como el fruto en el mediano o largo plazo - dependiendo en cada caso- de la construcción de una economía nacional que es eficiente, flexible y capaz de generar un gran y rápido crecimiento del excedente de recursos para inversión ${ }^{32}$. Algunas de las sugerencias hechas para aquella política de desarrollo nacional son las que siguen:

i) La integración económica latinoamericana, en vez de concentrarse en liberar el comercio y facilitar la subsidiarización de la región por el capital extranjero, debería hacerlo en el desarrollo de sectores productivos básicos (fierro, petroquímica, etc.) bajo el control multinacional latinoamericano.

ii) La agricultura debe hacerse eficiente y se debe redistribuir ingreso hacia la población agrícola.

iii) La propiedad por parte de corporaciones multinacionales de cliversas empresas en el sector exportador tradicional, trae consigo una serie de consecuencias adversas; por tanto es necesario la intervención estatal, o la nacionalización (si se requiere) complementada con la asociación de los países exportadores.

${ }^{30}$ Ref. (9) .

31Ibid.

s2Ibid. 
iv) Corporaciones multinacionales en los nuevos sectores manufactureros persiguen políticas que restringen el desarrollo de las exportaciones de manufactuxas, y dan lugar a altos costos en términos de divisas. Así, deben diseñarse nuevos modelos para la absorción de tecnología extranjera, que además permitan el clesarrollo tecnológico autóctono, tales como los "acuerdos de coproducción" entre FIAT y la Unión Soviética, KRUPP y Hungría, etc.

v) La política industrial debe estar basada en la creación de grandes unidades especializadas capaces de asegurar económías de escala y de financiar investigaciones y desarrollo. Esto se puede unir a la sugerencia de firmas multinacionales latinoamericanas, y acuerdos de coproducción; pero esto además trae consigo la necesidad de idear formas de control social sobre aquellas unidades, que al mismo tiempo permita un financiamiento creativo y eficiente.

Este enfoque representó una quiebra con la corriente principal del pensamiento de la Cepal al nivel de conceptualización y de sugerencias de políticas. Los "cuatro mecanismos de dependencia" de Sunkel son casi los mismos identificados por Cepal como los factores principales que impiden el proceso de desarrollo en la región. Pero él reformula estos factores a nivel global del proceso económico latinoamericano, donde se convierten en elementos de un sistema cuya característica principal es la dependencia externa. Una continuación del modelo de desarrollo prevaleciente, nos llevaría a una mayor dependencia y "subsidiarización" de la economía. Las soluciones basadas en la mera liberalización del comercio y de las políticas financieras de los países desarrollados sólo hacen -en el caso (improbable) que se realicen-, más viable el modelo "centroperiférico" en vez de sobreponerlo. Las sugerencias de políticas se caracterizan por su énfasis en i) la necesidad de cambiar la estructura de producción interna que produce los mecanismos de dependencia, y ii) la necesidad de cambios institucionales, principalmente respecto de las corporaciones multinacionales que refuerzan los mecanismos de dependencia.

Este enfoque tiene elementos en común con las formulaciones de la dependencia prevalecientes a principios de los años 60 en el Caribe. La visión cognoscitiva ${ }^{33}$ preanalítica de aquellas formulaciones estuvieron basadas en contrastes, o sea, contraste entre una imagen de una economía nacional e independiente, representada por los países metropolitanos desarrollados, y la realidad de dependencia de las economías de Ias Indias Occidentales. Estas economías eran descritas como descansando en el mundo exterior para ciertos elemen-

33para una discusión interesante de "visión de conocimiento preanalítica", un análisis económico, ver O. Sunkel, Ref. (3), p. 84, y J. Schumpeter, The Fistory' of Economic Analysis, Oxford University Press, Nueva York, 1954, pp. 41-42. 
tos vitales del proceso económico, y como altamente vulnerables a las condiciones externas. Así, Ia primera consideración de los asociados al New World Group al describir la economia de Guyana, fue que:

"Las principales fuentes generadoras de ingreso son de propiedad extranjera y dependientes de expertos, habilidades, mercados y capitales extranjeros..."34

Thomas comienza su análisis de la estructura monetaria en una economía dependiente, distinguiendo los factores de adaptación -aquellos que afectan "el grado en que la economía es capaz de adaptarse a-los cambios que ocurren en el resto del mundo", de factores generadores- aquellos que afectan "el grado en que la economía depende del resto del mundo para mantener y aumentar niveles internos de empleo, producto, demanda..."35. Los dos conjuntos de factores operan de forma que es posible clasificar la economía guyanesa como dependiente. Mc Intyre señala que:

"Los territorios de las Indias Occidentales son... aún considerados como ejemplos sobresalientes de economías dependientes. Son altamente dependientes del resto del mundo para los mercados de su producción, importan una amplia variedad de bienes que requieren, y descansan en otros paises para las transferencias de ingreso y capital, servicios bancarios y financieros, habilidades técnicas y de negocio, y aun para ideas sobre ellos mismos. ${ }^{36}$

El énfasis en estas formulaciones tendía a ser sobre la dependencia estructural ${ }^{37}$ del sistema económico y de los procesos económicos más importantes. El corolario necesario de aquella dependencia externa es la falta de interdependencia estructural interna entre muchos de los elementos más importantes del sistema económico. Brewster en un corto artículo sobre el concepto de dependencia económica, dio luz sobre el problema:

"La dependencia económica se puede definir como la falta de capacidad para manipular los elementos operativos de un sistema económico. Tal situación está caracterizada por la ausencia de interdependencia entre las funciones económicas del sistema. Esta falta de interdependencia implica que el sistema no tiene dinámica interna que le podría permitir funcionar como una identidad independiente y autónoma".38

${ }^{34}$ Ref. (3), p. 242.

${ }^{35}$ Ref. (4), p. 3.

${ }^{38}$ Ref. (5), p. 165 .

${ }^{87}$ En el sentido usado por Mc Intyre, o sea, dependencia que se logra como resultado de la estructura de la economía.

${ }^{a 8}$ Ref. (10), p. 1. 
Tal aproximación va más allá de las formulaciones que enfatizan la dependencia en el mundo exterior, y hace posible analizar y apreciar la anatomía de la dependencia a través de sus características y consecuencias en el funcionamiento interno de la economía en cuestión. En medir la dependencia así definida Brewster observa la irrelevancia de usar medidas ortodoxas como los coeficientes de importaciones y exportaciones, la proporción entre inversión extranjera y nacional, o la proporción entre propiedad extranjera y nacional. Prefiere usar en cambio una matriz de interrelaciones entre las funciones económicas operativas del sistema. Al aplicar esta medida a la economía de Trinidad-Tobago, él calcula coeficientes de correlación entre empleo, tasas de salarios, exportaciones, tasa de importaciones, producto, consumo, precios e inversión. Los resultados son casi sin excepción insignificantes, y este es el mejor carácter distintivo entre una economía dependiente como Trinidad-Tobago y una economía que depende del comercio exterior como Inglaterra". ${ }^{39}$

De lo anterior emerge el cuadro de las economías caribeñas con un mayor grado de dependencia estructural externa, y falta de interdependencia interna, que América Latina. Lo que es común para ambos enfoques es el método estructural. Tal como en el trabajo de Sunkel, había en el enfoque caribeño un elemento institucional. Esto es evidente en el problema sobre las consecuencias adversas para el desarrollo económico nacional, de las operaciones de las subsidiarias de corporaciones multinacionales en los principales sectores de exportación y en el sistema bancario ${ }^{40}$. Así, puede parecer sorpresivo que las proposiciones para la reforma estructural en las Indias Occidentales a principios de los años 60, fueron caracterizados, tal como en el trabajo de Sunkel, por un énfasis en la necesidad de cambiar las estructuras de producción interna y formas institucionales para iniciar la construcción de un sistema económico nacional. Las proposiciones de economistas de las Indias Occidentales para racionalizar las exportaciones agrícolas, para una mayor intervención estatal en el sector minero, y para el desarrollo de sectores industriales básicos, en un marco integrado bajo el control nacional, son muy similares a aquellos dados por Sunkel. ${ }^{41}$

El método institucional y estructural llegó a ser una de las características más importantes de la revolución en el pensamiento económico de las dos regiones a mediados y fines de los años 60 . $\mathrm{La}$ evolu-

${ }^{30}$ Ref. (10), p. 3.

${ }^{40}$ Ref. (3) y (4), también N. Girvan, The Caribbean Bauxite Industry, Mona, Institute of Social and Economic Research, University of West Indies, 1967, and Social and Economic Studies, 1970, Mona, Institute of Social and Economic Research.

${ }^{41}$ Ver referencia anterior, además de Ref. (7). 
ción del pensamiento generalmente tomó la forma de: i) añadir al método estructural e institucional una perspectiva y análisis histórico, ii) darle al método histórico-institucional-estructural el contexto teórico y empírico necesario para construir una teoría general de la dependencia y el desarrollo. El análisis siguiente arroja alguna luz sobre las similitudes y diferencias en estos desarrollos en las dos regiones y las razones de ello.

\section{El método histórico-estructural-institucional}

Probablemente las primeras y más comprensivas contribuciones para entender el proceso latinoamericano usando el método histórico estructural institucional se basan en el trabajo de Celso Furtado. E1 primer trabajo de Furtado trata la historia económica de Brasil y Iuego la teoría de desarrollo y subdesarrollo. De un artículo publicado en 1965, en que analiza las causas de la declinación del proceso de industrialización latinoamericana, se puede resumir sus proposiciones de la siguiente manera:

"En los modelos teóricos actualmente en boga así como en "las bases de las políticas de desarrollo se supone implícitamen“te que el sistema económico está integrado por una combina"ción de relaciones estructurales. Su estabilidad relativa resulta "de la existencia de un marco de referencia estructural y del "hecho de que los hombres y grupos sociales, en un esfuerzo "de maximizar su ingreso, descansan en su propia experiencia, "prefiriendo vías ya conocidas. Esto hace estadísticamente po"sible que se pueda predecir su comportamiento..."

También está implícito en este modelo teórico que si se mantienen un nivel adecuado de empleo, existe una relación causal necesaria, o compatibilidad, entre el comportamiento más probable estadísticamente de grupos sociales y la maximización del bienestar social, en cuanto este último concepto se define en términos de variables macroeconómicos. Un conjunto de señales políticas que registran las tensiones estructurales más significativas aseguran que la compatibilidad arriba mencionada sea mantenida a través de una introducción oportuna de correcciones en el marco institucional.

Contrariamente a este modelo, el marco institucional que prevalece en América Latina produce una estructura de distribución del ingreso responsable de un comportamiento incompatible con la más racional utilización de los recursos existentes... Hay una inconsistencia entre los intereses de aquellos grupos que controlan el pro- 
ceso de formación de capital y el interés de la comunidad como un todo. Como estos grupos ocupan posiciones estratégicas en el sistema de poder, no es una sorpresa que las señales políticas sean inadecuadas para registrar las tensiones estructurales... la médula del problema reside en las relaciones estructurales que determinan el campo en que las decisiones relevantes son tomadas. ${ }^{22}$

Para identificar el marco institucional y las relaciones que constituyen el centro del problema, se necesita del método histórico.

"Los supuestos estructurales que sirven como marco social para "el análisis económico, provienen de las evidencias históricas "que están creando las economías nacionales".‡3

Para este fin Furtado distingue tres períodos históricos en América Latina: i) el período colonial, ii) el período del "desarrollo orientado externamente", y iii) el período de industrialización sustitutiva, o del desarrollo orientado internamente: Cada período tiene instituciones económicas, características y un proceso económico característico. En la época de la colonia hay: a) latifundios de exportación agrícola, o sean plantaciones con esclavos, y b) exportación de metales preciosos; ambos forman las bases de la economía de exportación colonial. Hay además, latifundios que producen alimentos para el sector exportador. Los tres son resultados de la parcelación de la tierra nativa, recursos naturales y mano de obra, entre los colonizadores. Después del colapso de la economía de exportación colonial, los latifundios se retrotraen en unidades de producción de autosuficiencia, constituyendo unidades agrarias pre-capitalistas o semi-feudales llamadas fazendas. Esto creó una reserva de tierra y mano de obra para la expansión, que llega con el desarrollo orientado externamente.

El gran auge del comercio internacional en el siglo xxx asociado con la revolución industrial de los países de Centro da la oportunidad de la reintegración latinoamericana en la economía internacional como oferente de productos primarios. Los agentes de esta integración son la clase burguesa comercial urbana, que nació en el período colonial, y las inversiones extranjeras. Para servir esta demanda aparecen a) exportaciones agrícolas capitalistas, o sea plantaciones, b) agricultura ganadera capitalista de exportación, y c) economías de enclave minero exportador. Las operaciones de exportación agrícola pueden hacer uso de las fazendas como reservas de factores. Obtienen de ahí una: oferta prácticamente ilimitada de mano de obra a

${ }^{42}$ Ref. (II) .

${ }^{43}$ Ref. (1I). 
cualquier salario sobre el nivel de subsistencia prevaleciente, que se usa ya sea para operaciones corrientes o inversión de capital, ya que la expansión de capacidad es altamente intensiva en mano de obra ${ }^{44}$. Esto significa que no hay restricciones de oferta en la expansión de exportaciones; pero también implica la continuación de un bajo nivel general de salarios. Esto significa que el alto grado de concentración del ingreso establecido en el período colonial es reproducido en la fase del desarrollo orientado externamente.

El resultado de la crisis de 1929 es reducir la tasa de utilidad en el sector de exportaciones agrícolas, y aumentarla en el embrionario sector industrial, que hasta ahora se há limitado a la producción de bienes de consumo simple. Esto anuncia el período del desarrollo orientado internamente. Capital y empresarios fluyen hacia el sector industrial, reciben varias formas de ayuda estatal y los productores del sector trabajan más intensamente sus instalaciones. Todo estó resulta en un más o menos rápido crecimiento de la industrialización sustitutiva, en bienes de consumo. Pero la transición a la producción de bienes de capital e intermedios, tiene varias dificultades debido al alto coeficiente de capital en estas actividades. Primero, el contenido importado de las nuevas inversiones es alto, y esto presiona la balanza de pagos. Esto contrasta con el período de desarrollo orientado externamente donde el grueso del contenido de las nuevas inversiones se producia internamente. En efecto, el crecimiento industrial está ligado al crecimiento de exportaciones ${ }^{45}$. En vez de lo último, hay un aumento de la deuda externa. Segundo, el alto coeficiente de capital de la nueva actividad industrial significa que la capacidad de absorción de mano de obra es baja, y esto agrava el problema del desempleo. Tercero, puesto que la proporción de las utilidades en este sector es más alto que en la industria de bienes de consumo, su incremento resulta en un aumento de las utilidades en el ingreso nacional. Esto refuerza, una vez más, la alta concentración de ingreso, con el resultado de que el mercado nacional continúa siendo limitado por la existencia de una demanda altamente restrictiva para los bienes de consumo masivo. Cuarto, como el mercado nacional es pequeño, están limitadas las economías de escala del nuevo sector, por tanto su tasa de beneficio es baja. Todo esto significa que la economía no puede sostener la segunda fase de industria-

4En el ejemplo dado por Furtado, él supone que el $90 \%$ de los costos de expandir las operaciones agrícolas consisten en gastos de mano de obra, $y$ sólo el $10 \%$ consiste en costos de maquinaria y equipos.

${ }^{45}$ Como Sunkel dice, el sector de exportaciones tradicional se convierte, en efecto, en el sector productor de bienes-capital de la economía en esta etapa, por su rol como generador de divisas necesarias para comprar bienes de capital importados. Ver Ref. (9). 
lización sustitutiva, y sobreviene el estancamiento. Incluso esto empeora; las consecuencias sociales de estas dificultades resultan en el aumento de tensiones sociales y políticas que se transforman en adversas para el crecimiento económico.

Se puede observar que este análisis hizo uso de variables que son comunes en el análisis económico convencional, como el coeficiente de capital, la tasa de beneficios y el nivel de salarios. Pero localizar el comportamiento de tales variables en un contexto estructural e institucional, de tal manera de mostrar cómo su interacción condiciona el funcionamiento de la economía, especialmente en relación a su propensión al crecimiento o al estancamiento. Más aún, muestran cómo los parámetros institucionales y estructurales cambian a través del tiempo, de acuerdo a la relevancia del método histórico.

Ya hemos visto que la experiencia del crecimiento o declinación de la industrialización sustitutiva, en lo que Furtado se refiere, estaba limitada al grupo de los países latinoamericanos más grandes y más desarrollados. En un subsecuente artículo, Barros de Castro, afirma que estos países estuvieron capacitados sólo después de la crisis de 1930 para obtener un desarrollo industrial sustitutivo, porque habían establecido las condiciones necesarias para ello antes de las crisis ${ }^{ \pm 6}$. Desarrolla luego una tipología de actividades de producción para un análisis de la fase de desarrollo orientado hacia el exterior, distinguiendo de acuerdo a la intensidad en la utilización de mano de obra, recursos naturales (incluyendo la tierra) y capital. Esta macrofunción de producción, usada en el contexto de las circunstancias particulares, históricas y geográficas de los distintos países y áreas latinoamericanos, analiza tal fenómeno como un desequilibrio sectorial y espacial ${ }^{\star 2}$; la estructura social y el modelo asociado de distribución, y por tanto de demanda. Uno de los resultados es mostrar las condiciones bajo las cuales algunos paises, tales como Brasil y Argentina, desarrollan sus sectores industriales en la fase de desarrollo orientado hacia el exterior. Esto se debió a la existencia de mercados nacionales lo suficientemente grandes como para absorber manufacturas y el estímulo proveniente de las depresiones periódicas del mercado internacional. Otro resultado es el de poner de relieve la continua "marginalización" de las grandes masas de habitantes aborígenes a través de la fase ya sea de desarrollo orientado hacia el exterior o hacia el interior. Así, dicha técnica permite el estudio de la variedad de estructuras y experiencias económicas en el continente.

${ }^{6}$ Ref. (12), p. 103.

${ }^{~ " O}$ sea, amplias diferenciales de productividad e ingreso entre sectores económicos y áreas geográficas. 
Sunkel ${ }^{48}$ hace distinciones similares referentes a la estructura $y$ modelos de crecimiento, en la experiencia total latinoamericana. Él observa que el modelo de cambios estructurales asociados al desarrollo orientado hacia el exterior depende fundamentalmente de la capacidad del sector exportador de diversificación de la economía nacional y la reacción de la economía interna ante el sector exportador. Esto está determinado por varios factores: i) la duración de la expansión del sector permitida por las condiciones internacionales de mercado y la capacidad de oferta interna, ii) la función de producción del sector, que afecta no sólo el empleo extensivo de los distintos factores y la distribución del ingreso entre ellos, sino que además la utilización de materias primas provenientes de otros sectores, iii) la organización de la producción en ese sector, tomando en cuenta si hay un gran número de pequeños o medianos productores o un pequeño número de grandes productores y el grado de integración vertical entre las unidades productivas y el mundo exterior. La capacidad de reacción de la economía interna se ve afectado por i) la flexibilidad del sistema económico heredado de la época colonial y ii) el grado en que el Estado asegura una participación creciente en los ingresos del sector exportador y organiza un mercado nacional. Haciendo uso de estas herramientas, es capaz de lograr distinciones significativas no sólo entre el grupo de países que desarrollan su base industrial al antes de 1929 y el grupo que no lo hizo, sino también dentro de los grupos de países.

En las Indias Occidentales, el método de análisis estructural institucional, nació como se ha visto, a principios de los años 60 , como respuesta a la necesidad de comprender la falla de las políticas económicas de post-guerra para internalizar el proceso de crecimiento, y la persistente dependencia externa de las economías. Uno de los puntos sobre los cuales existía consenso entre aquellos que usaron el método, era trasladar la responsabilidad del subdesarrollo dependiente, desde las causas naturales, como el tamaño a las variables societales y por lo tanto, manejables, tal como las. instituciones. Best ${ }^{49}$ se hace la siguiente pregunta, cuando critica la tesis de que el tamaño pequeño, limita la transformación potencial de la economía: ¿Están los países grandes automáticamente mejor situados para explotar sus dotaciones de recursos que los pequeños países? ¿No podría haber un proceso de innovación que permitiera la transformación plena de una pequeña economía? ¿No puede ser que las experiencias y los recursos de un pueblo en particular, en un lugar determinado, los una a expresar un conjunto cualitativamente distinto de pre-

${ }^{18}$ Ref. 13, pp. 317-355.

${ }^{4}$ Ref. (14), pp. 30-34. 
ferencias del resto, además de tener distintos medios para obtener sus objetivos? ¿Y no parece que "es inherente a la estructura de las corporaciones internacionales que operan en la región el que la economía caribeña se mantenga. fragmentada y desintegrada?" Si las respuestas a las preguntas fueran afirmativas, entonces los obstáculos cruciales para la transformación serían identificados como la naturaleza de las instituciones políticas económicas, la estructura de preferencias y la tecnología. Las implicaciones necesarias para la política económica sería la reorganización de las instituciones para permitir la transformación de la estructura de producción, el desarrollo de una tecnología autóctona y la definición interna de las metas y preferencias sociales.

En parte para contestar estas preguntas, Best y Levitt emprendieron un amplio estudio de investigación sobre la economia caribeña ${ }^{50}$. La clave sobre el método a elegir fue otorgada por una observación anterior: "la industria azucarera tradicionalmente, ha sido, y es aún hoy, el principal puntal de la economía colonial. La estructura y carácter de la sociedad y economía ha sido modelada para que satisfaga sus necesidades. La propiedad y gestión han estado siempre en manos extranjeras; ha sido dependiente del capital y pericia extranjeros y de mercados imperialistas protegidos (formal o informalmente). Esta ha sido hasta hace poco, la mayor influencia sobre las políticas públicas... Las estructuras de producción (la importancia limitada de la producción para el consumo doméstico) y de demanda (la gran importancia de la demanda de importaciones) puede ser explicada en términos de la historia de la industria azucarera...".51

Es la historia de la industria azucarera, o mejor dicho el sector de plantaciones, que sirve de base para el trabajo de Best-Levitt sobre economía caribeña. Así:

"Hemos pensado estudiar los problemas económicos contemporáneos en la perspectiva del desarrollo pasado de la economía caribeña. Con este fin, empleando un modelo de histoire raisonnée, hemos construido una serie de modelos. Como una interpretación de la historia económica, estos modelos se pueden concebir como etapas sucesivas en la evolución de una economía de plantación.

Debemos enfatizar, sin embargo, que nuestro principal interés reside en aislar las estructuras institucionales y las restricciones que la economía contemporánea ha heredado del sistema

${ }^{s}$ Ref. (15) .

${ }^{51}$ Ref. (3), p. 244. 
de plantaciones. Estas etapas históricas, modelos, deben ser vistas en la perspectiva contemporánea como capas sucesivas de estructuras heredadas y mecanismos que condicionan las posibilidades de transformación de la econommía actual".

"... Es el estudio del carácter del sector de plantaciones y su relación con el mundo exterior y con la economía nacional que provee la comprensión. esencial del mecanismo de la economía caribeña. ${ }^{2} 2$

Se distinguen tres etapas en la evolución de la economía de plantación caribeña: i) Economía Pura de Plantación; desde alrededor de 1600 a 1838; ii) Economía Modificada de Plantación, desde 1838 a 1938; iii) Economía Remodificada de Plantaciones; desde 1938. La economía de plantación tuvo su origen en una de las formas de penetración metropolitana en el Nuevo Mundo. Es una especie de "Economía de Ultramar" de las metrópolis europeas, La economía se compone en su mayor parte de plantaciones, y la actividad de plantación es virtualmente toda la actividad económica. Así el funcionamiento de la Economía Pura de Plantación, cualitativamente puede representarse por el funcionamiento de cualquier plantación. Cada plantación está ligada a una casa de comercio (Merchant House) metropolitana dentro del marco de una compañía de comercio. La metrópoli provee la organización y gestión; el capital, transporte, ofertas y mercados; Africa provee de mano de obra y el Caribe de tierra. El Caribe es por tanto, nada más que el centro de producción de un sistema triangular de comercio y producción en que el centro de la iniciativa es la metrópoli, y el centro de control, los comerciantes.

Como cada plantación asegura su oferta y dispone de su producto a través del factor externo, no hay transacciones entre plantaciones dentro de la economía. No hay una interdependencia estructural en una economía a base de plantaciones, ya sea entre unidades productoras, o entre unidades productoras y consumidoras. 'Todos los efectos secundarios o terciarios de desarrollo de la actividad de plantación, en la forma de ingreso o creación de una demanda, y. formación de fondos de ahorro e inversión, se localizan en la metrópoli. La Economía Pura de Plantación, por tanto, ayuda a la transformación de la economía metropolitana de la que es parte; concebida como una entidad separada permanece estructuralmente dependiente $\mathrm{y}$ endémicamente subdesarrollada. ${ }^{53}$

52Ref. (15), Vol. I.

"Ver Ref. (15), Vol. 1. Además Lloyd Best, "A model of Pure Plantation Economy", Social and Economic Studies, Mona, Institute of Social and Economic Research, University of the West Indies. Vol. 17, No 3, Septiembre 1968. 
En la primera mitad del siglo xrx a los esclavos africanos se les da libertad legal, la Preferencia Imperial para la plantación se elimina a medida que Gran Bretaña entra a la gran era de libre comercio. Las dificultades que esto trae para las actividades de plantación hacen necesario ajustes al sistema; tal como el establecimiento de un campesinado negro en tierras no aptas para plantaciones, importación de mano de obra de India, y la racionalización del sector de plantación. No hay transformación económica genuina, en gran parte por la herencia de la Economía de Plantación Pura. Como el gobierno continuaba siendo para y por la clase de los plantadores, las políticas gubernamentales son hostiles al desarrollo de la agricultura nacional y de la industria de artesanía. Las políticas referidas a la infraestructura, tierra, inmigración, educación, investigación y comercio, son todas adaptadas al sector de plantaciones. Más aún, si un campesino logra establecerse debiclo a la disponibilidad de tierra. no apta para plantaciones, lleva consigo de la Economía Pura de Plantación una herencia de gustos con un alto contenido importado y por ende restringen la demanda de productos nacionales. Por último, la expansión del campesinado, y de la agricultura nacional, es controlada por la continua dominación del sector de plantaciones sobre las mejores tierras. Así la economía Modificada de Plantaciones pudo tener una dinámica interna mayor como un resultado del campesinado, pero su capacidad de transformación sigue siendo sistemáticamente frustrada.

Durante el período contemporáneo nuevas modificaciones son introducidas a la economía. Estas consisten en el surgimiento de una nueva y altamente valorada corriente de exportaciones, tal como bauxita, petróleo, turismo; de manufactura nacional en algunos países, y de un sector público activo. Sin embargo muchas de las características de la Economía Pura de Plantación se repiten en este período. Esto es así porque el carácter de las nuevas instituciones en el sector privado -las corporaciones multinacionales- guardan muchos de los rasgos de las compañías de comercio. Las CMN (corporaciones multinacionales) combinan en una sola mano organización, capital, tecnología y capacidad empresarial; además muestran un alto grado de integración vertical. El Caribe ahora se convierte en el centro de abastecimiento de materias primas (bauxita, petróleo), de consumo de servicios (turismo) y de armaduría de bienes finales (manufactura). Así los mercados de productos y factores se encuentran desarticulados, lo que sucede tanto entre países como entre regiones de un mismo país. Una vez más, y con una fuerza aún mayor, el Caribe se convierte en parte de las Economías de Ultramar del sistema económico metropolitano: esta vez por el intermedio de las corporaciones multinacionales. La transformación estructural 
es impedida sistemáticamente por la herencia estructural de la Economía Pura de Plantaciones; y por las características estructurales del nuevo mercantilismo de las corporaciones multinacionales. Un gobierno "activo" significa una ayuda activa a este sistema, ya que el gobierno busca darles facilidacles a las firmas metropolitanas, que son percibidas como agentes de la industrialización y modernización. El gobierno, aclemás, asume la responsabilidad de la creación de empleo remunerado que la Industrialización por Invitación no fue capaz de proveer: ${ }^{54}$

Las similitudes cle este "enfoque" con el histórico-estructuralista de América Latina son de inmediato evidentes. Ambos se basan en el uso de la teoría económica, y en el énfasis que se le da al rol de las instituciones internas y las relaciones exteriores en el condicionamiento de las estructuras y el funcionamiento del proceso económico. En algún grado las razones para las similitudes pueden deberse al intercambio intelectual entre las dos regiones ${ }^{55}$. En el fondo, tales similitudes se deben al hecho de que los economistas encontraron que el enfoque histórico-estructural-institucional era un método de análisis poderoso ${ }^{5 \theta}$. En este sentido, ha sido el fruto de una continua búsqueda de conceptos y métodos analíticos que fuesen más provechosos para la comprensión, y que por lo tanto posibilitaran influenciar el funcionar de las economías ${ }^{57}$, que las teorías en boga en el mundo metropolitano.

${ }^{5} \mathrm{Hay}$ que hacer notar que este proyecto idea marcos contables para representar a la "Economía Pura de Plantaciones" y "Economía de Plantación Modificada". Ver Ref. (I5) .

${ }^{55}$ Best y Levitt indican que su trabajo "está en la tradición del enfoque estructural comenzando por Furtado, Prebisch y otros en América Latina, por Innis en Canadá, y por Myrdal, Chenery, Seers y otros en paises metropolitanos". Ref. (15), Vol. 1. Además del contacto que tuvo Levitt con Sunkel.

${ }^{5 e} \mathrm{E} 1$ uso de este método ha llegado a ser muy amplio en el estudio del desarrollo y subdesarrollo en otros paises del Tercer Mundo. Así el Instituto Africano para el Desarrollo Económico y Planificación patrocinante de una conferencia sobre estrategias de desarrollo en Africa vs. América Latina en Septiembre de 1972, observó que: "un enfoque puramente económico" al subdesarrollo no permite un entendimiento ni de la morfologia ni de la dinámica del subdesarrollo. Hay una creciente conciencia respecto al hecho de que para entender las fuentes de subdesarrollo y estudiarla más cientificamente se requiere que el problema del desarrollo se trate tanto desde el punto de vista histórico social y político como económico. Estudiar la historia del desarrollo del Tercer Mundo no significa solamente volver al pasado, sino que es indispensable para la investigación de las razones por las que nuestros paises siguen siendo hoy subdesarrollados, y para identificar los obstáculos para el desarrollo".

${ }^{57}$ Esta búsqueda tenía además un aspecto cuantitativo, en la forma de la construcción de modelos matemáticos de las economias latinoamericanas y caribeñas. Para el Caribe, ver artículo por Seers, Brewster Taylor, de Castro y Burce, en varios artículos de "Social and Economic Studies" desde 1964. Para Latino- 
Cuando consideramos el contenido actual de estos análisis, se hace evidente una apreciable coincidencia en las experiencias históricas, institucionales y estructurales de ambas regiones. Se observa una distinción de períodos históricos aproximadamente iguales que se pueden presentar esquemáticamente como sigue:

\begin{tabular}{|c|c|c|c|}
\hline & $1600-1850$ & $1850-1930$ & Después de 1930 \\
\hline Sunkel & Mercantilismo & - Liberalismo & $\begin{array}{l}\text { Neo-mercanti- } \\
\text { lismo }\end{array}$ \\
\hline $\begin{array}{l}\text { Furtado/CEPAL } \\
\text { (América Latina) }\end{array}$ & $\begin{array}{l}\text { Economia Colo- } \\
\text { nial de exporta- } \\
\text { ción }\end{array}$ & $\begin{array}{l}\text { Desarrollo orien- } \\
\text { tado hacia el ex- } \\
\text { terior }\end{array}$ & $\begin{array}{l}\text { Desarrollo orien- } \\
\text { tado hacia el in- } \\
\text { terior }\end{array}$ \\
\hline Best y Levitt & $\begin{array}{l}\text { Economía Pura } \\
\text { de Plantación }\end{array}$ & $\begin{array}{l}\text { Economia Modi- } \\
\text { ficada de Planta- } \\
\text { ción }\end{array}$ & $\begin{array}{l}\text { Economía } \\
\text { de Plantación } \\
\text { Remodificada }\end{array}$ \\
\hline
\end{tabular}

La sobreposición que se da en los tipos de estructuras económicas e instituciones proviene principalmente debido a la definición y significación de i) agricultura de plantación, ii) enclave minero exportador y iii) corporaciones multinacionales. Furtado ${ }^{58}$ y Sunkel 50 han reconocido las consecuencias adversas de la agricultura de plantación para promover clesarrollo industrial vía la estructura de distribución del ingreso y su patrón asociado de demanda y su rol en la promoción de la depenclencia externa. El trabajo de Best y Levitt es un análisis comprensivo del proceso de una economía de plantación con esclavos, y su papel no sólo en la creación cle una estructura deforme y subdesarrollada sino que también en condicionar adversamente la evolución subsiguiente de las economías donde ella es predominante. Backford ${ }^{60}$ en un importante trabajo examina los efectos de distintas formas de agricultura de plantación en un análisis de lugar y tiempo. Parte de la premisa de que la naturaleza de las instituciones de una sociedad agricola son cruciales. Primero, porque el camino al desarrollo (o subdesarrollo) está altamente determinado por la naturaleza de la organización y del desempeño cle su sector agrícola. Segundo, porque la naturaleza de una socieclad más amplia y su forma de gobierno está altamente influenciada

américa ver O. Sunkel y A. Calcagno (editores) América Latina: Modelos Matemáticos, Santiago, Editorial Universitaria, 1971.

ssver especialmente "Economic Growth in Brazil".

sover lo que ha escrito sobre cconomía Cubana. Ref. (13), pp. 333-336.

${ }^{6}$ Ref. (16). 
por sus instituciones ruxales. La agricultura de plantaciones hace surgir dịstorsiones sistemáticas en la asignación de recursos desde un punto de vistá social, que trae consigo altos costos sociales. Además tiene efectos subdesarrolladores en la dinámica de la economía. Donde este es el sịtema predominante de la la utilización de recursos de la economía o subeconomía, hay subdesarrollo crónico, y pobreza persistente para los habitantes. Además la cultura de una sociedad de plantaciones exhibe una estratificación social de castas, donde las clases están altamente correlacionadas con la raza y la movilidad vertical está limitada. El sistema político está caracterizado por una administración altamente centralizada y una tradición autoritaria. Beckford no trata sólo con plantaciones de esclavos, sino que también con aquellas que emplean mano. de obra asalariada, inquilinos, y compañías multinacionales de plantaciones. Analiza también las relaciones entre campesinos y plantaciones; y describe este tipo de sistemas en Asia, África y los Mares del Sur como también en el Caribe, noreste brasileño $y$ el sur norteamericano.

En el siglo $x x$, emergen algunos importantes enclaves mineros de exportación en el área del Caribe, asociados a la extracción de petróleo y bauxita, operados por corporaciones multinacionales verticalmente integradas. La preocupación de Girvan ${ }^{61}$ es mostrar cómo este tipo de industrias contribuyen a i) una dependencia económica; ii) la naturaleza de enclave de la industria, y ijii) el fracaso de la industria para generar las transformaciones en la economía anfitriona, aun cuando el Eștạdo tiene éxito en captar una gran parte del excedente que ésta genera. Las firmas multinacionales internalizan. su propia dinámica de crecimiento por tiempo indefinido, a través de estrategias tales como integración vertical, diversificación y alteración de sus fuentes de abastecimiento. El alto grado de integración vertical implica que la subsidiaria es totalmente dependiente de la casa matriz. Realiza con ella la mayoría de las transacciones de mercaderías y de capital, en vez de efectuarlas con la economía nacional. El aumento de las imposiciones y de la intervención estatal, en un esfuerzo para integrar la industria en la economía nacional, es la señal para la casa matriz para el cambio a fuentes alternativas de materias primas ${ }^{62}$. Esto implica una eventual disminución en el crecimiento del sector minero exportador. Los esfuerzos estatales para transformar la economía con el uso de los ingresos provenientes del sector minero, encuentran un éxito limitado, en parte por las deseconomías externas del sector minero-exportador en el

${ }^{\circ}$ Ref. (17) .

${ }^{02}$ Este movimiento también es ọcasionado por el aumento de los costos de extracción asociados con el agotamiento de los recursos minerales que se pueden obtener fácillmente. 
crecimiento del producto agrícola y manufacturero. El sector minero quita mano de obra y tierra a la agricultura, sus altos niveles de salarios aumentan el precio de oferta de la mano de obra para la agricultura y manufactura. Promueve un patrón de demanda de bienes agrícolas y manufacturados altamente diversificado, y además aporta divisas que facilitan la competencia de los bienes importados con los nacionales. Así las economías de exportación de minerales tienden a exhibir el fenómeno de "crecimiento de la dependencia sin desarrollo".

Los escritores caribeños se limitaron al análisis intensịvo y extensivo, de las estructuras-agricultura de plantaciones y enclaves mineros-exportadores, que son considerados en Latinoamérica como variantes en un modelo más general. En el proceso, las distinciones entre la teoria $-y$ las economías mismas- latinoamericana y caribeña, se ha disipado.

Partiendo de esta observación la sobreposición de los esquemas históricos, institucionales y estructurales puede ser llevado a un contexto más amplio, que integra las experiencias económicas de las dos regiones en un marco de referencia común de dependencia y subdesarrollo.

Las economías latinoamericanas y caribeñas han sido integradas desde el siglo xvi en el mismo sistema económico internacional dominado por el Atlántico Norte. Cambios estructurales en este sistema internacional precipitaron la emergencia de nuevas etapas en las economías dependientes de ultramar anexadas a él. Las variaciones en las formas precisas y en los patrones de crecimiento de dependencia y subdesarrollo se deben principalmente a: a) variación en las causas y necesidades de la expansión externa del Atlántico Norte y b) el traslado de los centros de dominación metropolitana $y$, las diferentes necesidades de distintos centros. La época del mercantilismo europeo fue por implicancia la época de la gran colonización americana. La colonización creó instituciones rurales que diferían de acuerdo a sus necesidades: plantaciones con esclavos para productos tropicales, encomiendas para metales preciosos y para el abastecimiento de bienes de consumo interno, y familias con terrenos y viviendas para colonización. En esta forma se creó la economía colonial de exportación en América Latina. A medida que crecía el poder anglo-francés, las plantaciones con esclavos se trasladaban gradualmente desde el Noreste brasileño hacia las Indias Occidentales, creándose aquí una Economía Pura de Plantación y dejando al primero en un estado crónico de subdesarrollo y pobreza. La erosión de la economía colonial de exportaciones de Latinoamérica llevó a un retroceso parcial a formas semi-feudales de organización. 
El surgimiento de la hegemonía en el siglo xxx significó condiciones favorables para la independencia latinoamericana y su consiguiente reintegración en la economía internacional: este hecho está intimamente asociado con el término del período colonial y con la fase del desarrollo orientado hacia el exterior. Esto trajo consigo además el desmantelamiento del sistema mercantilista. Por otra parte, implicó la destrucción de los fundamentos de la Economía Pura de Plantación en las Indias Occidentales y el surgimiento de modificaciones, particularmente en la forma de producción interna de alimentos y una economía artesanal. Paradojalmente, por lo tanto, este fue en ciertos aspectos un período de desarrollo orientado hacia el interior. A su vez el surgimiento de la economía norteamericana en el siglo xix, hizo que sus inversiones en plantaciones de azúcar se hicieran en las ex colonias españolas en el Caribe. Esto produjo la variante "caribeña hispánica" del "desarroHo orientado hacia el exterior" en donde Cuba es el caso clásico.

Ciertos tipos de estructura característica de la fase del desarrollo latinoamericano orientado hacia el exterior permitieron el nacimiento de un significativo mercado interno para manufacturas simples. En aquellos casos comenzó un proceso de industrialización incipiente, y cuando se produjo la crisis de 1929 tales países estaban preparados para emprender una industrialización sustitutiva. La gran depresión también precipitó cambios políticos en las Inclias Occidentales y subsecuentemente la Industrialización por Invitación.

Las Indias Occidentales iniciaron además durante este tiempo una nueva etapa de desarrollo orientado hacia el exterior. Por una parte, Gran Bretaña reaccionó a la crisis volviendo a un sistema preferencial, lo que permitió sustentar el sector agrícola tradicional de exportaciones. La hegemonía de U.S.A. y la expansión de ultramar creó necesidades de nuevos recursos básicos y cle servicios suntuarios (turismo). Este desarrollo dio lugar al aumento de la importancia de las corporaciones multinacionales de U.S.A. como las principales instituciones de la organización económica internacional. Tales corporaciones llegaron a dominar el proceso de industrialización sustitutiva en América Latina. En esta forma, ambas regiones se fueron progresivamente incorporando a un mismo sistema económico metropolitano en el período de post-guerra.

Este marco de referencia sugiere los elementos de una teoría general del desarrollo y subdesarrollo en el Nuevo Mundo. Un elemento de esta teoría sería el conjunto de tipologías de los sistemas de producción resultante del impacto y penetración metropolitanos. Así para el período colonial Best y Levitt distinguen hinterlands de colonización, de conquista y de explotación. Beckford desarro1la una tipología para mostrar su significación geográfica, étnica 
y cultural: América blanca ${ }^{63}$. Aquellos para la conquista son tierras montañosas: Indo-América y aquellos para la explotación son tierras bajas, tropicales: América Negra. ${ }^{64}$

Generalmente, han sido las regiones montañosas de Indoamérica y las regiones bajas de América Negra las que se han mantenido crónicamente subdesarrolladas desde el tiempo colonial. Principalmente como resultado de los sistemas de organización agrícola de explotación, y de las rígiclas estructuras raciales ${ }^{65}$. Las condiciones de la colonización en América blanca durante el siglo xIx -baja densidad de población, niveles relativamente altos de ingresos y su distribución más igualitaria- eran más favorables para el surgimiento de la industrialización. Este desarrollo fue posible sólo en los Estados Unidos debido a: el sistema igualitario de organización agrícola, a excepción del Sur, y su alta productividad; las dimensiones continentales del mercado, y la victoria del proteccionismo que siguió a la Guerra Civil. Así U.S.A. desarrolló una base industrial dinámica y junto a ella grandes corporaciones oligopólicas e integradas. Esto fue lo que permitió la temprana diversificación de las exportaciones, fuera de la base agrícola inicial, hacia productos manufacturados. Significó además, que los otros países de América templada, en el siglo $\mathrm{xx}$, adoptaron el proteccionismo y promovieron oficialmente la industrialización, las firmas norteamericanas ya habían desarrollado su organización, la tecnología y la fuerza financiera para internacionalizarse y participar en el proceso de substitución en el extranjero, contribuyendo al nuevo modo de dependencia que surgió en estos países.

Otro elemento complementario sería la naturaleza de las organizaciones, necesidades y cambios estructurales de las economías metropolitanas que dominan el sistema económico internacional y que por tanto condicionan la evolución de las economías dependientes. Autores latinoamericanos, especialmente Cardoso y Faletto ${ }^{66}$ y Dos Santos ${ }^{67}$ desarrollaron el concepto de dependencia para sugerir que

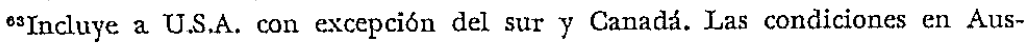
tralia y Nueva Zelandia eran esencialmente similares.

${ }^{64}$ Corresponde también al área de América dedicada a las plantaciones $\mathrm{e}$ incluye el sur de U.S.A.

${ }^{60}$ México un pais Indọamericano montañoso que ha experimentado un desarrollo considerable en el siglo 20, es la excepción que prueba la regla. México sufrió una revolución de la segunda década del siglo que dio como resultado una reforma agraria, que creó un mercado interno, y el control de los recursos básicos especialmente petróleo.

${ }^{\circ} \mathrm{F}$. H. Cardoso y E. Faletto: Dependencia y Desarrollo en América Latina, México, siglo Xxi, 1969. Especialmente Cap. 1-2.

${ }^{87}$ T. Dos Santos, Dependencia y Cambio Social, Santiago, Ceso, 1970, Cap. 3 y 4 especialmente. 
el análisis no es completo sin una especificación de ambas partes del sistema global dominante. La dependencia ya no es vista como "datum externo" sino como un estado de cosas en que la acción recíproca de la economía interna, variables sociales y políticas están condicionadas por factores que funcionan en el sistema; pero que están determinadas externamente a él.

Esto estaba implícito en la teoría que analizá la evolución de las economías caribeñas y latinoamericanas como condicionadas a través de reacciones reflejas al sistema económico internacional. Siguiendo los avances hechos por Cardoso y Faletto; y Dos Santos, Furtado explora las implicaciones para la teoría económica. Sugiere que ésta ofrece una manera de quebrar el impase en la teoría del desarrollo entre aquellos que buscan desarrollar una nueva teoría económica aplicable a países subdesarrollados y aquellos que apoyan la "universalidad" de las ciencias económicas. Si las economías subdesarrolladas son de hecho sub-sistemas dependientes de las economías desarrolladas, un marco teórico apropiado debe tratar con el sistema como un todo. No se puede tratar significativamente al sub-sistema dependiente por sí solo. Ni para la misma materia, sólo el sistema independiente. Esto significa que "la teoría del subdesarrollo, se convierte esencialmente en una teoría de la dependencia". ${ }^{88}$

Para Furtado, el mecanismo tal vez central de dependencia-subdesarrollo, es el hecho de que los grupos de medianos y altos ingresos en sub-sistemas dependientes definen "desarrollo" y "progreso" como la adquisición de pautas de consumo originados y prevalecientes en los sub-sistemas desarrollados dominantes. En la fase anterior a los años 30 en las economías de América Latina, los bienes requeridos para servir a esta demanda eran importados directamente. En la fase contemporánea son localmente manufacturados con insumos importados. Al ser su producción, intensiva en capital, el crecimiento industrial en los sub-sistemas dependientes se caracteriza por un coeficiente de capital creciente: esto aumenta la concentración de ingreso, limita la amplia difusión del progreso tecnológico y sus frutos a la población. Además provoca una progresiva marginalización de las masas latinoamericanas. Al ser las corporaciones multinacionales las que controlan los medios para satisfacer este consumo, el desarrollo para los países subdesarrollados es siempre "internacional", en el sentido que, en la gran mayoría de los casos, está atado a la expansión de las actividades de una empresa, cuyo centro de decisiones está fuera del sub-sistema en cuestión ${ }^{69}$. Finalmente, el marco de optimización neo-clásico no se puede aplicar ni a los sub-sistemas

"ssibid, p. 336.

${ }^{89}$ Furtado, Ref. (18), p. 346. 
dependientes o el sistema global, en la medida que el concepto de optimalidad "esté ligado a la función de bienestar social, que presupone autonomía de decisiones de parte de la colectividad"70. Tal autonomía no existe en el mundo donde el comportamiento del consumidor es manipulado y condicionado por las acciones de grandes corporaciones.

En un artículo que apareció simultáneamente ${ }^{71}$ Sunkel adelanta proposiciones hacia la construcción de un cuadro global de la polarización económico-política y social. Su tesis es que los cinco temas de desarrollo, subdesarrollo, dependencia, marginalidad y desequilibrios geográficos, a los que se recurre constantemente en las ciencias sociales en América Latina, pueden considerarse como aspectos inter-relacionados del mismo proceso.

"La evolución de este sistema global de desarrollo-subdesarrollo dentro de un período de tiempo, ha dado origen a dos grandes polarizaciones que han encontrado su mayor expresión en términos geográficos. Primero: una polarización del mundo entre los países desarrollados, industrializados, avanzados, nórdicos centrales por un lado, y los subdesarrollados, pobres, dependientes y periféricos dẹ sur, por otro. Secundariamente, una polarización en los países entre grupos, regiones y actividades, avanzados y modernös por una parte y atrasados, primitivos, marginales y dependientes por otra. La principal diferencia entre las dos estructuras, es que la desarrollada, debido básicamente a su capacidad de crecimiento endógeno, es la dominante, mientras que la subdesarrollada, debido en gran parte al carácter inducido de su dinamismo, es dependiente". ${ }^{72}$

Dos clases de relaciones deben ser exploradas: i) las relaciones internacionales que originan la polarización internacional, ii) las relaciones internas que dan origen a la polarización interna. El primer conjunto está asociado principalmente con los problemas del modelo Centro-Periférico de comercio internacional y el consiguien'te modelo de dependencia de industrialización sustitutiva. Las relaciones son institucionalizadas por conglomerados transnacionales -la infraestructura del sistema- y un complejo de organizaciones internacio: nales inter-gubernamentales que constituyen su superstructura.

La clave para la comprensión de las relaciones de polarización interna se basan en el reconocimiento que los grupos avanzados "modernos" en las estructuras dependientes subdesarrolladas, derivan sus altos ingresos de a) su asociación con actividades ligadas a estructuras desarrolladas, y b) explotación interna de la masa de la po-

70Ibid., p. 349 .

${ }^{71}$ Sunkel, Ref. (19). Ambos autores reconocen la influencia del intercambio intelectual en la escritura de los dos artículos.

i2Ibid., p. 1. 
blación. Los grupos avanzados están más integrados social y culturalmente con las estructuras desarrolladas que con los grupos marginales de sus propios países. Son, por tanto, parte de la estructura desarrollada en un sentido global. Esta integración y marginalidad tienden a quebrar los conceptos tradicionales de clases. Algunos trabajadores y capitalistas son parte del sistema internacional, otros trabajadores, pequeños capitalistas, desempleados o subempleados, son marginados. Esto origina un proceso dual de integración transnacional y desintegración nacional; que subyace al proceso de polarización interna $\mathrm{e}$ internacional. Estas proposiciones de Furtado y Sunkel, dan algunos pasos significativos hacia la formulación de la naturaleza del sistema global, cuyas manifestaciones similares son desarrollo-dominación y subdesarrollo-dependencia. Además, como Furtado observa, tienen algunas implicaciones interesantes para la teoría económica. La emergencia de escuelas de "Centro-Periferia", estructuralistas y de "dependencia" provino de la preocupación para desarrollar teorías autóctonas, más aplicables a la realidad latinoamericana y caribeña que Ios modelos metropolitanos en boga. El análisis del subdesarrollo condujo a uno sobre dependencia, $y$ esto a su vez a uno sobre el sistema global incluyendo las economías metropolitanas. Esto significa que la economía metropolitana tiene una parte crucial en la comprensión de la dinámica del subdesarrollo.

¿Por qué entonces, la nueva teoría económica comenzó con una reacción en contra de la teoría metropolitana en vez de tomarla como punto de particla? Parece que la razón para esto, no fue que la teoría metropolitana era irrelevante para países subdesarrollados, sino más bien irrelevante para los paises desarrollados mismos. Los modelos de crecimiento que suponen una economía cerrada, tal como los del tipo Harrod-Domar, ampliamente difundidos, oscurecen el rol de las relaciones internacionales en el proceso de desarrollo de los países avanzados y por tanto no ponen atención sobre los efectos de aquellas relaciones en los países subdesarrollados. Las teorías de la firma $\mathrm{y}$ de la industria basadas en la noción de la pequeña firma competitiva incapaz de influenciar los mercados de factores o bienes y que operan dentro de los límites nacionales, no ofrecen una perspectiva de la operación de las plantaciones y latifundios, ni de las corporaciones multinacionales. Las teorias de comercio internacional basadas en el supuesto de competencia perfecta, completa movilidad interna de factores productivos $y$ paridad en las relaciones de poder internacional, no exponía los efectos desiguales de aquel comercio sobre los diferentes países participantes. De esta manera no se podía dar alguna luz sobre los efectos subdesarrolladores de la división internacional del trabajo en los países primarios exportadores. La búsqueda 
Norman Girvan / Teorías de dependencia económica en el Garibe y Latinoamérica

de una teoría relevante para los países subdesarrollados se convierte también en la búsqueda de una teoría válida y relevante para los países metropolitanos. En el desarrollo y dependencia, los economistas de los países subdesarrollados dependientes han contribuido a la reformulación de una teoría metropolitana y una teoría global del capitalismo. ${ }^{73}$

\section{CONGLUSIONES}

Uno de los resultados de este estudio es el confirmar la proposición de que la teoría económica para ser válida debería siempre comenzar con una observación de la realidad, más precisamente, debería identificar la historia y las instituciones, que delimitan los parámetros dentro de los cuales los procesos económicos tienen lugar ${ }^{74}$. Más aún, una vez que se establezca la teoría, debería mantenerse sensitiva a los cambios históricos e institucionales que alteran los parámetros originalmente identificados. La "nueva teoria" debería, por tanto, ser cuidadosa de no convertirse en una "nueva ortodoxia" que sobreviva a la realidad para explicar la cual fue originalmente diseñada. Una de las preguntas que surgen de este estudio es la aplicabilidad de los métodos empleados en el Caribe y América Latina al análisis del subdesarrollo en Africa y Asia. ¿Hasta dónde el estudio de la historia, instituciones y estructuras del subdesarrollo dependiente, es relevante en esas regiones, y hasta qué grado las experiencias de estas regiones pueden ser integradas con las del Nuevo Mundo para construir una teoría general del subdesarrollo? La respuesta a estas preguntas podría constituir una base para la colaboración entre los estudiosos.

La implicancia más importante e inmediata de los análisis revisados en este trabajo, parece caer en el campo de la formulación de políticas. Las nuevas formulaciones al problema del subdesarrollo dependiente surgieron como vimos, de la frustración de los modelos de la post-guerra y la necesidad de encontrar nuevas políticas. Cualquier diagnóstico de las causas de un problema económico implica la naturaleza de la solución requerida ${ }^{75}$. Si se considera al sub-

${ }^{\pi}$ El trabajo de tales economistas ha engarzado el de economistas metropolitanos, como Galbraith, Kymer y' Gunder Frank.

${ }^{7}$ SSchumpeter observó las herramientas del análisis económico, como una historia económica, sociología económica, teoría económica y estadísticas económicas y consideró la historia económica como la más importante de las cuatro. Ver Historia del Análisis Económico.

${ }^{76}$ Ver Sunkel, Ref. (13), pp. 16-17. 
desarrollo como el resultado de la escasez de capital, la solùción implicará la necesidad de aumentar la oferta de capital. Si el problemia se define como sobre-población, esto implica la necesidad de disminuir la tasa de crecimiento de la población ${ }^{78}$. Un análisis del subdesarrollo que sè centra en los efectos de la historia, instituciones, estructura y relaciones económicas exteriores, trae consigo soluciones de largo plazo y que deben estar basados en cambios institucionales, de la estructura productiva, de la naturaleza de las relaciones económicas externas. La mayoría de los trabajos a que hemos referido contienen sugerencias de esta índole.

No todos los que concuerdan que la participación en el sistema capitalista internacional produce el subdesarrollo dependiente, estarán de acuerdo sobre la posibilidad de un desarrollo independiente. Vania Bambirra, discutiendo las perspectivas de un desarrollo socialista en América Latina donde la industrialización en bienes de capital e intermedios aún no se encuentra establecida, dice que:

"Tal situación significa que la implantación del socialismo requiere en estos países un esfuerzo interno mucho más intenso, hasta que el desarrollo de los sectores claves se logra. Esto sería completamente posible por medio de una economía política planificada que promoviera la utilización intensiva de recursos naturales. Para que esto suceda en un periodo corto de tiempo es necesaria una contribución financiera, científica y teórica sustancial de los países socialistas. Si esta no ocurre el proceso de industrialización sufriría un proceso de discontinuación seguido por un largo período de crisis económica. Como el socialismo es un sistema internacional, todos los recursos necesarios seguramente estarían disponibles. En este caso, la industrialización continuaría dependiendo de insumos provenientes del exterior. Pero el proceso no sería uno de acumulación dependiente sino que esencialmente distinto, uno de reproducción socialista basado en relaciones de intercambio y cooperación entre países libres. En el caso de los países donde el proceso que puede llamarse de industrialización, no ha comenzado aún -el caso de Cuba- las contribuciones científicas y tecnológicas de los países socialistas deben ser intensas por un período largo. ${ }^{77}$

Esta es precisamente la alternativa que Sunkel ha rechazado en la búsqueda de una política de desarrollo nacional. En algún grado la elección entre la integración socialista internacional y políticas de desarrollo nacional, descansarían en cuestiones básicas sobre la

${ }^{7}$ Realmente la necesidad es de disminuir el tamaño absoluto de la población. A pesar de que los economistas no quieren ver esto como la solución lógica, lá política exterior en USA., especialmente en Vietnam, parece estar inspirada en este aserto.

TIbid., p. 69. 
ideología. Conviene preguntarse si la alternativa de la integración socialista internacional no sólo no resuelve el problema del diseño de la estrategia para internalizar el proceso de crecimiento, sino que lo evade por entero. La verdadera "dependencia" de esta opción es que hace las estrategias de desarrollo del país en cuestión, dependiente de la política económica internacional de los estados socialistas, y por ende, dependiente de las estrategias nacionales de estos estados. ¿̨Cuán posible es de hecho una estrategia de desarrollo que descanse en el supuesto de la ayuda automática, de la naturaleza, calidad y cantidad necesaria, de un conjunto de paises extranjeros? ¿Se puede suponer, en el ejemplo específico usado, que países como Chile automáticamente encontrarán un lugar para el desarrollo de industrias de bienes de capital e intermedios en el bloque socialista internacional? En el caso cubano, esto aún no ocurre: la estrategia ha sido expandir las exportaciones primarias tradicionales y desarroIlar exportaciones primarias adicionales. Sin embargo esta pregunta trae consigo la necesidad de otra línea de investigación: la de las relaciones económicas internacionales y estrategias de desarrollo dentro del bloque socialista.

Una apreciación de las líneas de políticas dadas por los trabajos revisados probablemente llevaría a concluir que se sugiere en el mejor de los casos, una línea de aproximación general para la definición de la estrategia de desarrollo. Las preocupaciones más generales son la reforma agraria, nacionalización y/o socialización, el rompimiento de las ataduras económicas internacionales. Manejarlas con un grado razonable de eficiencia económica es difícil, y no hacen nada más que establecer algunas pre-condiciones para los cambios estructurales. El cambio estructural, el desarrollo de una base tecnológica nacional y un sistema económico razonablemente flexible en tareas de largo plazo que no reditúan beneficios de inmediato. Más aún, para un país cualquiera tales cambios estructurales requieren la formulación precisa de una estrategia de desarrollo a la luz de la estructura específica de subdesarrollo dependiente, y de las posibilidades específicas que pueden ser sustentadas por los recursos, potencial de la economía nacional y el conjunto prevaleciente de circunstancias internacionales. 78

${ }^{8} \mathrm{De}$ nuevo, la experiencia cubana sugiere algunas lecciones importantes sin despreciar los enormes avances sociales hechos por la revolución: tomó más de 10 años encontrar la estrategia de desarrollo apropiada y racional. Los líderes revolucionarios, al ser informados que una visión que asociaba subdesarrollo con monocultura y falta de industria, disminuyeron la producción de azúcar e invertieron en industrias. Esto redujo la capacidad de importación y aumentó la demanda por importaciones. Esto indujo el retorno al modelo anterior y a un gran esfuerzo para expandir la producción de azúcar. Lo que involucra altos costos de oportunidad, especialmente en el empleo de mano de obra. La estrategia para la década 
Un aspecto de la estrategia de desarrollo, al que muchas veces no se le concede la suficiente importancia es la estructura deseada de consumo a que aspira la sociedad. Si la meta es "alcanzar a los países ricos", y "achicar la brecha", los modelos de consumo a que la sociedad implícitamente aspira son aquellos de las sociedades avanzadas. Los fines del desarrollo, por tanto, serán esencialmente de imitación. Pero supónese que es precisamente este modelo de imitación ¿el portador de la dependencia? Más específicamente, si la. estructura económica está diseñada para ofrecer los bienes de consumo característicos de los países desarrollados, necesitará de insumos, marcas registradas, tecnología y bienes de capital e intermedios provenientes de las firmas y economías donde dichos bienes de consumo se originan. La implicancia es continuar la dependencia de la tecnología externa y creación de gustos; y ciertamente de un proceso de condicionamiento cultural que no solamente es externo al estado-nación, sino que además deriva su dinámica y su naturaleza exclusivamente de las necesidades de corporaciones transnacionales privadas responsables solamente ante ellas mismas. Tal dependencia, es verdad, puede no estar asociada con la marginalización, pobreza o miseria humana, o con la propiedad extranjera y la estructura de producción. Pero ello tampoco significa necesariamente que las generaciones futuras no la consideren como menos objetables, o los problemas que origina menos perniciosos.

del 70 es por tanto de mecanizar la producción azucarera y desarrollar otras exportaciones para poder diversificar. Esto, se argumenta, ilustra la necesidad de análisis especificos para encontrar formulaciones precisas de estrategias de desarrollo apropiados para nuestros países. 